\title{
INFORMAÇÃO E NOVAS FERRAMENTAS À PESQUISA
}

\author{
Everson Luiz Zingano Júnior*
}

SÍNTESE - Ao longo dos séculos as ferramentas de trabalho evoluíram constantemente $e$ as ferramentas que se destinam à manipulação de informações não são diferentes. O surgimento da Informática e de recursos e conceitos que a impulsionaram, como o computador pessoal, a interface gráfica e a multimidia, revolucionaram os processos tradicionais de criação e disponibilização de informações. O Folio Views é um exemplo de ferramenta de informação de última geração e está sendo utilizado pelo Projeto Integrado Urbanidade e Cidadania.
Abstract - Throughout the centuries the working tools constantly evolve and thus the tools designed to manipulate data are not different. The introduction of the Computers Science and some concepts and resources that boosted it, such as the personal computer, the graphic interface and the multimedia, revolutioned the traditional process of creating and deploying data. The software named Folio Views is an example of last generation data tool and it is used by the "Projeto Integrado Urbanidade e Cidadania".

Vivemos atualmente na chamada Erra da Informação. Toda e qualquer atividade humana, independente de seu caráter, em alguma parte do processo que a caracteriza, utiliza-se de algum tipo de informação e/ou gera algum tipo de informação. Existem atividades analíticas cuja matéria-prima e produto final são informações. Atividades mais tradicionais, como as comerciais e industriais, utilizam informações ao longo de sua execução.

A denominação de Era da Informação não é gratuita. Nossa sociedade avançou tremendamente no desenvolvimento de ferramentas que facilitem a manipulação de informações em diferentes áreas. Além disso, graças a algumas destas ferramentas, a informação foi democratizada. Isto é, a informação não é mais privilégio de algumas classes e está ao alcance de uma quantidade cada vez maior de pessoas.

Dentre as ferramentas tradicionais de informação, podemos citar a escrita e as técnicas de impressão, que permitiram que o conhecimento acumulado por nossa espécie fosse preservado com maior qualidade, sem ter de depender de métodos menos eficazes como, por exemplo, a tradição oral, que é comum para a preserva-

Bacharelando em Informática pela PUCRS, bolsista PIBIC/PUCRS, vinculado à linha de pesquisa "Formação, Trabalho, Instituiçăo", orientado pela prof Julieta Beatriz Ramos Desaulniers.

\begin{tabular}{|l|l|l|l|l|l|}
\hline VERITAS & Porto Alegre & v. 42 & $\mathrm{n}^{\mathbf{0}} 2$ & Junho 1997 & p. 277-281 \\
\hline
\end{tabular}


ção de informações culturais de uma sociedade, mas não seria tão eficiente para a preservação da Teoria da Relatividade de Albert Einstein, por exemplo.

Os meios de comunicação têm papel muito importante na disseminação de informações. E a Informática é uma das responsáveis diretas pela revolução que se processou em nossa sociedade a partir da segunda metade deste século.

O computador pode ser visto como uma ferramenta de armazenamento de informações e de processamento de informações. No início, devido ao seu custo, o computador era privilégio de poucos, principalmente governos e empresas caracterizadas por alavancar as atividades de pesquisa e desenvolvimento em áreas diversas. Com o surgimento do microcomputador e seu desenvolvimento até os patamares atuais, a utilização do computador também foi democratizada. Atualmente podemos pensar na utilização de computadores em quase todos os ramos de atividades, senão todos.

Dentre as vantagens obtidas pelo uso do computador estão a grande capacidade de armazenamento de informações e a velocidade com que estas informações são processadas e os resultados disponibilizados. A capacidade de armazenamento de informações foi estendida ao infinito pela utilização de tecnologias como o CD-ROM. Além disso, a disponibilização de informações pode se dar nos mais variados formatos: planilhas, listas, relatórios, gráficos comparativos, etc.

Estas vantagens agregadas às novas tecnologias de computação fazem com que o microcomputador se torne uma ferramenta excelente para qualquer manipulação de dados. Dentre as tecnologias mais recentes na área de Informática, a interface amigável e a multimídia, que estão diretamente relacionadas, são responsáveis diretas pelo crescimento no uso do computador, principalmente no setor doméstico.

A interface amigável pode ser melhor exemplificada pelo ambiente operacional denominado Microsoft Windows. Anteriormente, a utilização de computadores implicava aprender comandos e regras presos a uma sintaxe rígida, onde o menor equivoco na sua utilização resultava em mensagens de erro enigmáticas. Este ambiente hostil de operação resultava em grande resistência ao uso de computadores e na restrição de seu uso aos ambientes de trabalho.

O Microsoft Windows revolucionou o mercado de computadores padrão IBM (que são os mais utilizados no Brasil, também devido à reserva de mercado de Informática que vigorou no país até 1992), ao incorporar características que já eram consolidadas em computadores de sistema diferente, como o Apple MacIntosh.

A grande diferença estava num ambiente de operação atrativo ao usuário comum, já que incorporava recursos gráficos que não eram explorados anteriormente, como ícones e imagens coloridas, som e vídeo. Além disso, era um ambiente que apresentava coerência: a maioria dos programas, apesar de destinados a atividades diferentes, apresentava uma "aparência" em comum e métodos de operação iguais ou similares. Isto facilitava a operação de diferentes softwares e mesmo o aprendizado destes softwares, pois estes incorporavam elementos que, uma vez compreendidos e assimilados pelo usuário, eram recorrentes em diversos programas. 
A difusão do Windows e de seus sucessores ajudou no fortalecimento de outras tecnologias. A multimidia foi uma das tecnologias mais beneficiadas. Ocorre que o computador armazena qualquer tipo de informação da mesma maneira: em bytes. Isto significa que se o usuário for armazenar um texto, uma imagem e uma música no computador, eles serão convertidos em bytes, que são a unidade básica de manipulação de informações pelo computador. Cada tipo de informação é trabalhado por um programa ou método diferente, mas, em termos de armazenamento, os arquivos são similares. Esta facilidade em armazenar e manipular formatos diversificados foi aproveitada em uma tecnologia que agregava estes formatos diversos sob uma estrutura comum. Surgiu assim a multimídia.

A multimídia utiliza-se, basicamente, de texto, imagens, sons e vídeos ou animações criadas por computador. A combinação destes elementos é comum, mesmo em meios mais tradicionais de comunicação ou informação, e faz com que as informações que estão sendo transmitidas sejam fortalecidas ou corroboradas por outras informações em formato diferente. Tomando por exemplo um artigo de uma revista, podemos ter a combinação de textos e imagens.

A multimídia proporciona a expansão das mídias tradicionais. Uma crítica de um filme ou disco pode ser apresentada com o texto e com trechos do trabalho que está sendo criticado. A maior dificuldade era o tamanho das informações. Um texto é armazenado em arquivos pequenos, mas sons, imagens e principalmente vídeos resultam em arquivos muito grandes. Assim, a distribuição destas informaçỗes fica dificultada pelo meio de distribuição.

A idéia de se disponibilizar grandes volumes de informações, como uma enciclopédia, por exemplo, tinha como único obstáculo a distribuição destas informações, que requereria uma quantidade enorme de disquetes. A utilização de CDS que ficaram conhecidos como CD-ROMs removeu definitivamente este obstáculo. Atualmente, podemos encontrar enciclopédias tradicionais em um ou dois CDROMs, ao passo que, no formato tradicional, estas enciclopédias necessitam de pelo menos 20 volumes.

Um dos recursos explorados pelas tecnologias de multimídia é o Hipertexto. A leitura não implica necessariamente seqüencialidade. Um texto pode abarcar diversas referências a outros textos. O leitor não precisa seguir uma seqüência tradicional de leitura, podendo evitar textos que não lhe interessam. O Hipertexto apresenta elos, que podem ser palavras-chave realçadas ou mesmo imagens que levam o usuário a outras informações. Isto faz com que uma enciclopédia multimídia seja de mais fácil utilização do que uma tradicional. Um verbete pode remeter a outro sem que haja a necessidade de se buscar um volume diferente na estante.

Some-se a esses aspectos o fator custo/benefício. O preço dos computadores é relativamente estável. Uma configuração considerada padrão está sempre na mesma faixa de preço. Pouco a pouco o computador assume um papel de eletrodoméstico, à medida em que fica cada vez mais atrativo para o consumidor comum.

O projeto integrado Urbanidade e Cidadania caracteriza-se pela utilização de um grande volume de informações. A necessidade de se disponibilizar estas infor- 
mações de uma maneira mais prática levou os responsáveis pelo projeto a procurarem ferramentas de Informática que facilitassem estas necessidades.

A idéia é disponibilizar o conteúdo total ou parcial (conforme a necessidade) de todos os documentos e fontes utilizados no projeto, bem como todos os documentos produzidos pelo projeto. Como as fontes utilizadas são diversificadas, é necessário que esta ferramenta manipule todos estes formatos diferentes de uma maneira integrada. Além disso, uma apresentação agradável e atrativa é recomendável.

Por todas estas características, a ferramenta escolhida foi o Folio Views. 0 Folio Views é um Gerenciador de Infobases - ele pode gerenciar grande volume de informações em formato livre, armazenadas em uma base de informações a qual é chamada de Infobase.

Para efeitos de comparação, podemos dizer que o Folio Views é um editor de textos (como o Microsoft Word) que incorpora recursos incomuns aos editores de textos tradicionais, como a possibilidade de utilização de elementos de multimídia (elos de hipertexto, objetos incorporados como som, fotos e vídeo, etc.) e um sofisticado mecanismo de localização de informações textuais.

O Folio Views permite que, ao conteúdo original do documento-alvo, sejam aplicados recursos de classificação rápida denominados de estruturas de pesquisa seletiva. Estes recursos são utilizados para a recuperação mais rápida das informações. Exemplos destes recursos são os campos, notas, níveis, destaques e elos.

Isto é particularmente importante no Projeto Integrado Urbanidade e Cidadania, pois o volume de informações é muito grande. A simples recuperação textual de um editor de textos comum torna o processo menos eficiente. O Folio Views permite que, além da recuperação textual, sejam utilizadas instruções de procura criadas com comandos de lógica booleana, caracterizada pelo uso dos operadores "E", "Ou", "Não" e "Oux" ("Ou Exclusivo").

Para aplicar com eficiência estes recursos no Projeto Integrado foi definida uma "ficha" de classificação do material. Esta "ficha" é composta de informações utilizadas na classificação de documentos em bibliotecas e arquivos. Todos os documentos que forem anexados à Infobase do Projeto deverão ser classificados com base nesta ficha. Algumas das informações da "ficha" não se aplicarão a alguns dos documentos e não serão apresentadas; mas nenhuma informação que não conste da ficha será utilizada, garantindo a uniformidade de classificação das informações.

Informações extras, como o estado de conservação dos documentos e o formato original dos mesmos, entre outras, serão apresentadas junto à "ficha" de classificação, através de elos de janelas.

Às informações da "ficha" de classificação serão aplicados "campos". Um mecanismo personalizado de procura será disponibilizado e utilizará estes "campos" para uma procura mais eficiente. Assim, ficará mais fácil localizar todas as referências a determinada palavra, assunto, autor ou fonte de informação.

O conteúdo da Infobase será apresentado de maneira uniforme, utilizando recursos gráficos como cores e formatação de texto (tipo de letra, tamanho, negrito, sublinhado, itálico, etc.). 
O Folio Views permite a distribuição da Infobase original para usuários e a utilização de uma Infobase personalizada. A partir da Infobase original, o usuário pode criar notas em trechos da Infobase ou mesmo marcar trechos, conforme for a sua necessidade. Estas notas e marcas também podem ser utilizadas no momento de pesquisar informações na Infobase.

Dentre as ferramentas de informação mais atuais, o Folio Views certamente ocupa lugar de destaque por facilitar ao extremo a criação e a disponibilização de grandes volumes de informação diversificada.

Para o usuário final das Infobases, o ganho está na facilidade e agilidade de recuperação de informações específicas dentro de um universo muito maior de informações, bem como na possibilidade de alterar a informação que foi recuperada e adequá-la ao seu uso ou gosto. 